\title{
Erratum to: Functional signatures of oral dysbiosis during periodontitis progression revealed by microbial metatranscriptome analysis
}

Susan Yost $^{1 \dagger}$, Ana E Duran-Pinedo ${ }^{1+}$, Ricardo Teles ${ }^{3}$, Keerthana Krishnan ${ }^{1}$ and Jorge Frias-Lopez ${ }^{1,2^{*}}$

\section{Erratum}

It has come to our attention that there is an error in the methods section of this article [1]. The sentence: "Quantified libraries were pooled and sequenced using the MiSeq v2, 2×150 cycle cartridge (Illumina)" is incorrect and should read: "Quantified libraries were pooled and sequenced using the MiSeq v3, $2 \times 75$ cycle cartridge (Illumina)". The publisher apologises for any inconvenience caused.

\section{Author details}

'Forsyth Institute, 245 First Street, Cambridge 02142, Massachusetts, USA. ${ }^{2}$ Harvard School of Dental Medicine, 188 Longwood Ave, Boston 02115, MA USA. ${ }^{3}$ University of North Carolina Chapel Hill, School of Dentistry, Chapel Hill 27599-7450, NC, USA.

Published online: 27 October 2015

\section{Reference}

1. Yost S, Duran-Pinedo AE, Teles R, Krishnan K, Frias-Lopez J. Functional signatures of oral dysbiosis during periodontitis progression revealed by microbial metatranscriptome analysis. Genome Med. 2015;7:27.

\footnotetext{
*Correspondence: jfrias@forsyth.org

${ }^{\dagger}$ Equal contributors

'Forsyth Institute, 245 First Street, Cambridge 02142, Massachusetts, USA

${ }^{2}$ Harvard School of Dental Medicine, 188 Longwood Ave, Boston 02115, MA, USA

Full list of author information is available at the end of the article
} 